\title{
Analytical comparison of topology configuration of wireless power transfer system
}

\author{
Jaros V., Drgona P., Kozacek B.,Piri M. \\ Department of Mechatronics and Electronics, University of Zilina \\ Institute of Electrical Engineering, University of Zilina \\ Zilina, Slovakia \\ Email: viliam.jaros@fel.uniza.sk
}

\begin{abstract}
This article deals with the description of topology configuration of wireless energy transfer system. Wireless energy transfer systems are used in several applications areas as is wireless charging accumulators in electric vehicles, charging batteries in mobiles, in lighting applications and other. This article is focused on wireless charging accumulators in electric vehicles, which the main quality indicators are high transmitted power, high efficiency and the transmission distance in range of the ground clearance of standard vehicles. There are described two topologies, first is series - series compensated system and second is series parallel compensated system
\end{abstract}

Keywords- resonant compensation, wireless energy transfer, transfer properties, efficiency, transmitted power

\section{INTRODUCTION}

Nowadays electrically powered automobiles obtain bigger interest in the automotive industry. Electric vehicles gain this interest thanks to high efficiency and ecological operation. In the case of the asynchronous motor, we can convert electrical energy into mechanical with $90 \%$ of the efficiency, what is much higher than efficiency of combustion engine, which has efficiency only $25-34 \%$. [1] Due to the power electronics and energy conversion systems together with development of new battery types contribute to the development and application of electric vehicles in the automotive industry. [2] The main disadvantage of the electric car is energy accumulation. Batteries are big, heavy with short lifetime and long charging times. Almost due to these reasons, it is necessary to solve a question about battery charging.

Wireless system uses electromagnetic field for energy transfer. Progress in the area of semiconductor converters allowed developing power supplies with high switching frequencies $(100 \mathrm{kHz}$ and more). [3][5] Together with this, a big attention is given on wireless charging systems due to its simple principal operation. You only need to come to the appointed place and system automatically starts to charge accumulators of electric vehicle, whereby charging

The authors wish to thank to Slovak grant agency VEGA for project no. 1/0579/14 - Research of topological structures of power electronics segments for system of wireless energy transfer. The authors wish also thank for extensive support with materials from Bel Power Solutions s.r.o. stations can be placed on various places, e. g. bus stops, crossroads, park, etc...[6]

In this article we are describing the system of wireless energy transfer with the use of mathematicphysical models for the most used compensation configuration of receiving and transmitting circuit. Efficiency and transmitted power are the most significant parameters for wireless battery charging in electric vehicles. From the component design point of view it is also important to have knowledge about values of voltages and currents in main circuit. At the end of the paper, the general recommendations for practical use of each variant are given. [7]

\section{MAGNETIC - RESONANT COUPLING OF WET SYSTEM FOR ELECTRIC VEHICLES CHARGING}

When we use transmission by magnetic resonance, the compensation capacitors are connected to transmitting and receiving coil. This means that the analysed circuit becomes a resonance circuit. For the practical application (battery charging) we analysed two basic configurations:

- Series-series compensation

- Series-parallel compensation

Each type of compensation is typical with its specific characteristics and transfer properties. In next chapter, the analytical expressions of efficiency and other important circuit parameters in dependency on frequency are being described. Instead of frequency, the mutual inductance (distance between transmitter and receiver) is also considered as variable parameter [8].

\section{A. Series - series compensation}

For series - series compensation the capacitor is connected in series with transmitter and receiver coil (Fig. 1). 


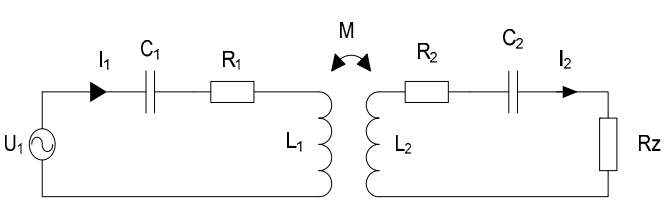

Figure 1. Equivalent circuit of WET with series - series resonant compensation

Mathematical model of series - series compensation is from complexity point of view much easier than other compensation types. Using the methodology of loop currents, we can express impedance matrix of this configuration (1).

$\left[\begin{array}{c}\dot{U}_{1 \_s s} \\ 0\end{array}\right]=\left[\begin{array}{cc}R_{1}+j\left(\omega L_{1}-\frac{1}{\omega C_{1}}\right) & -j \omega M \\ -j \omega M & R_{2}+R_{Z}+j\left(\omega L_{2}-\frac{1}{\omega C_{2}}\right)\end{array}\right) \cdot\left[\begin{array}{l}\dot{I}_{1} s s \\ \dot{I}_{2 \_s s}\end{array}\right]$

DC parasitic resistances of transmitting and receiving coils are represented by parameters $R_{1}$ and $R_{2}$. $L_{1}$ and $L_{2}$ represent inductances of coils and $M$ represents the mutual inductance, which is created between the coils $\mathrm{L}_{1}$ and $\mathrm{L}_{2} . \mathrm{R}_{\mathrm{Z}}$ is resistance of load and $\mathrm{U}_{1 \_ \text {ss }}$ is voltage of power supply.

From (1) the formula for current of transmitting and receiving part in complex form as (2) and (3) can be derived:

$$
\begin{aligned}
& \dot{I}_{1}=\dot{I}_{1 \_s s}=\frac{R_{2}+R_{Z}+j\left(\omega L_{2}-\frac{1}{\omega C_{2}}\right)}{\left[R_{1}+j\left(\omega L_{1}-\frac{1}{\omega C_{1}}\right)\right] \cdot\left[R_{2}+R_{Z}+j\left(\omega L_{2}-\frac{1}{\omega C_{2}}\right)\right]+(\omega M)^{2}} \dot{U}_{1-s s} \\
& \dot{I}_{2}=\dot{I}_{2 \_s s}=\frac{-j \omega M}{\left[R_{1}+j\left(\omega L_{1}-\frac{1}{\omega C_{1}}\right)\right]\left[R_{2}+R_{Z}+j\left(\omega L_{2}-\frac{1}{\omega C_{2}}\right)\right]+(\omega M)^{2}} \dot{U}_{1-S s}
\end{aligned}
$$

If circuit is supplied by harmonic voltage with frequency equal to resonant frequency, then for the previous formulas are valid:

$$
\begin{gathered}
\dot{I}_{1}=\dot{I}_{1_{-} S S}=\frac{R_{2}+R_{Z}}{R_{1} R_{2}+R_{1} R_{Z}+(\omega M)^{2}} \dot{U}_{1 \_S S} \\
\dot{I}_{2}=\dot{I}_{2 \_s S}=\frac{-j \omega M}{R_{1} R_{2}+R_{1} R_{Z}+(\omega M)^{2}} \dot{U}_{1_{-} S S}
\end{gathered}
$$

(4) and (5) show that circuit during resonance has only resistive character and circuit currents are given just by the parasitic resistances of coils, load resistance and supply voltage.

Values of the currents flowing through the coil and capacitor on the transmitting and receiving side (Fig. 2) (Fig. 3) are necessary for design of the wire diameter of the coil, which has direct impact on the parasitic resistances $R_{1}$ and $R_{2}$. For capacitor, in terms of losses, it is important to choose a capacitor with suitable ESR. With the increase of mutual inductance, the peak points of current $I_{2}$ slightly decrease. This means, that only with correct frequency control, we can achieve same charging current for different distances between coils.

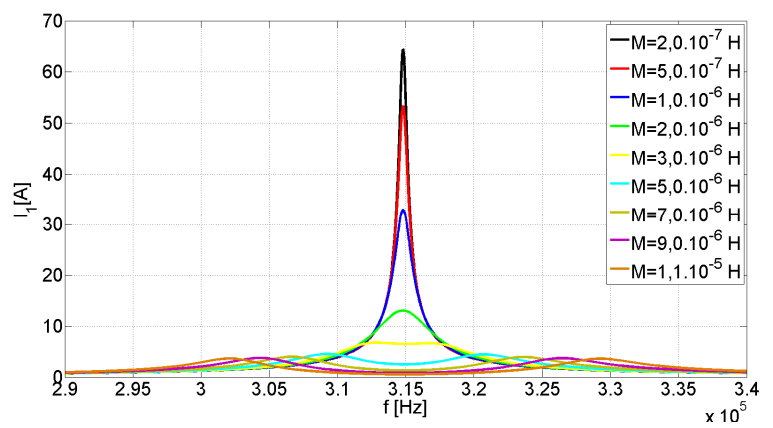

Figure 2. Frequency dependency of the current $I_{1}$ flowing at transmitting side of WET system with series - series resonant compensation

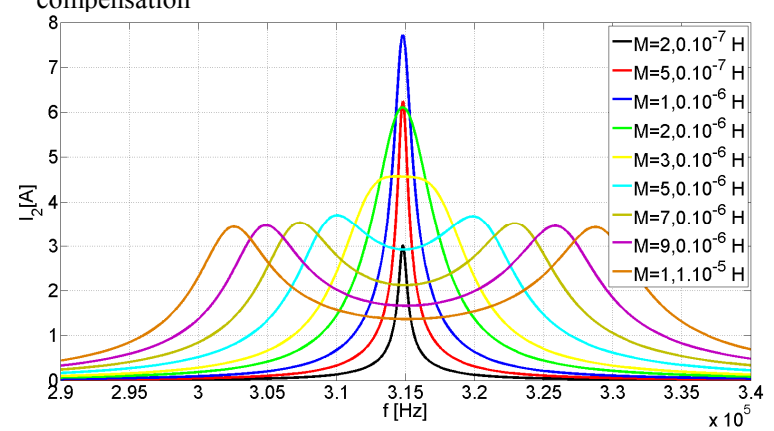

Figure 3. Frequency dependency of the current $\mathrm{I}_{2}$ flowing at receiving side of WET system with series - series resonant compensation

Phase shift between power supply voltage $U_{1}$ ss and current $I_{1}$ (Fig. 4) can by usable for control of wireless power system.

If phase shift between power supply voltage $\mathrm{U}_{1 \_s s}$ and current $I_{1}$ is equal to 0 , then maximum transmitted power is for higher values of mutual inductance on the same frequency except resonant frequency. For lower values of mutual inductance is maximum efficiency and transmitted power to the load on the resonant frequency, when phase shift between power supply voltage $\mathrm{U}_{1 \_ \text {ss }}$ and current $\mathrm{I}_{1}$ is equal 0 too.

This allows make control system with tracking maximum transmitted power.

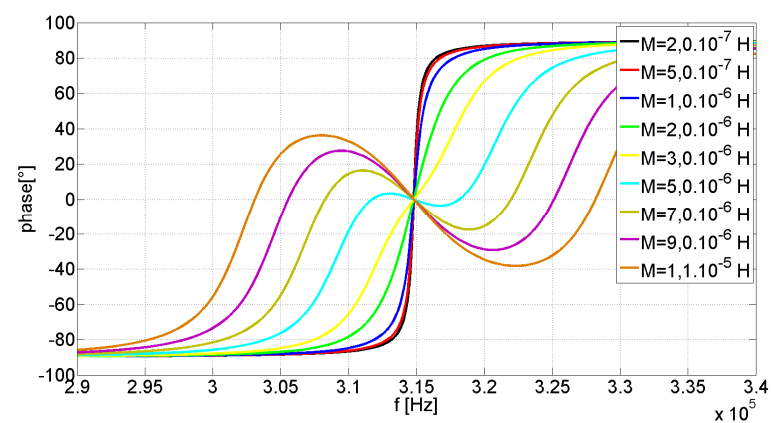

Figure 4. Phase shift between power supply voltage $\mathrm{U}_{1 \mathrm{ss}}$ and current flowing transmitting coil $\mathrm{I}_{1}$

In (Fig. 5) the frequency dependence of transmitted power to the load for various values of mutual inductance is plotted.

Transferred power to load is very low, for low value of mutual inductance and maximum is situated on the resonant frequency. Transmitted power to the load is increased with increasing mutual inductance between coils. For higher values of mutual 
inductance, transmitted power is no longer increased, but above a certain value slowly decreased.

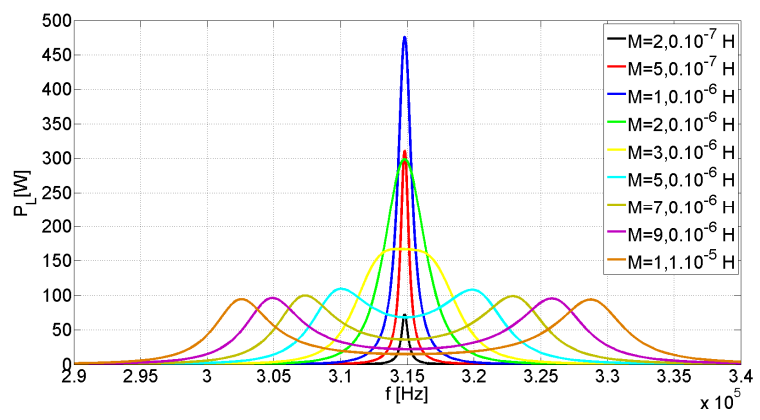

Figure 5. Frequency dependency of output power for WET system with series - series resonant compensation (variable parameter mutual inductance $\mathrm{M}$ )

For these cases the maximum isn't situated at resonant frequency, but is at frequencies determined by (6).

$$
f=\frac{1}{2 \pi \sqrt{(L \pm M) C}}
$$

For that reason it is better to supply mentioned circuit with the harmonic signal, whose frequency is determined by (6). If the value of mutual inductance changes, then maximal power transmission can be kept, when switching frequency of supply signal will be modified to the value given by (6).

In the (Fig. 6) the frequency characteristic of efficiency of S-S compensated system is shown.

The peak efficiency is achieved at the point of resonant frequency. The efficiency near resonant frequency is more than $90 \%$ for high values of the mutual inductance. The disadvantage is that the power delivered to the load is very low at this point. When considering efficient and proper battery charging process then the results is that we have transfer efficiency greater than $90 \%$ but power transfer capability is insufficient. Therefore the operation of the circuit is recommended with the frequencies given by (6). At these points it is possible to transfer much more power to the load (Fig. 5) at acceptable level of system efficiency $(80 \%-90 \%)$.

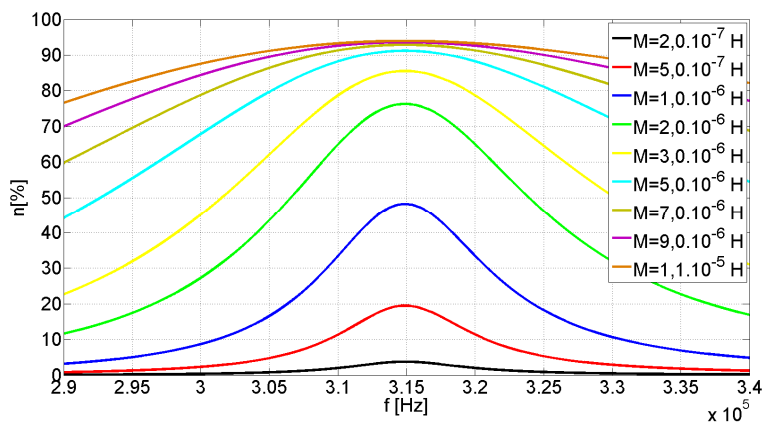

Figure 6. Frequency dependency of efficiency for WET system with series - series resonant compensation

\section{B. Series - parallel compensation}

Series - parallel compensation means that one capacitor is connected in series to the transmitting coil and other one is connected in parallel to the receiving coil (Fig. 7).

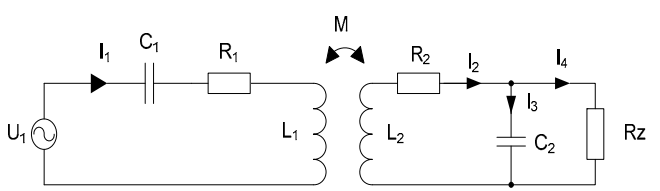

Figure 7. Equivalent circuit of WET with series - parallel resonant compensation

Using method of loop currents, we can express impedance matrix of SP-compensated circuit (7).

$$
\left[\begin{array}{c}
\dot{U}_{1 \_S P} \\
0 \\
0
\end{array}\right]=\left[\begin{array}{ccc}
R_{1}+j\left(\omega L_{1}-\frac{1}{\omega C_{1}}\right) & -j \omega M & 0 \\
-j \omega M & R_{2}+j\left(\omega L_{2}-\frac{1}{\omega C_{2}}\right) & j \frac{1}{\omega C_{2}} \\
0 & j \frac{1}{\omega C_{2}} & R_{Z}-j \frac{1}{\omega C_{2}}
\end{array}\right]\left[\begin{array}{c}
\dot{I}_{1} \leq S P \\
\dot{I}_{3}-S P \\
\dot{3}_{3} S P
\end{array}\right]
$$

If we substitute $\mathrm{Z}_{1}=\mathrm{R}_{1}+\mathrm{j} \cdot\left(\omega \mathrm{L}_{1}-1 /\left(\omega \mathrm{C}_{1}\right)\right)$ and $\mathrm{Z}_{2}=\mathrm{R}_{2}+\mathrm{j} .\left(\omega \mathrm{L}_{2}-1 /\left(\omega \mathrm{C}_{2}\right)\right)$ we can express the circuit currents as follows:

$$
\begin{aligned}
& \dot{I}_{1}=\dot{I}_{1_{-} S P}=\frac{Z_{2}+j \frac{1}{\omega C_{2}\left(j \omega C_{2} R_{Z}+1\right)}}{Z_{1} Z_{2}+\omega^{2} M^{2}+j \frac{Z_{1}}{\omega C_{2}\left(j \omega C_{2} R_{Z}+1\right)}} \dot{U}_{1_{-} S P} \\
& \dot{I}_{2}=\dot{I}_{2 \_S P}=\frac{j \omega M}{Z_{1} Z_{2}+\omega^{2} M^{2}+j \frac{Z_{1}}{\omega C_{2}\left(j \omega C_{2} R_{Z}+1\right)}} \dot{U}_{1_{-} S P} \\
& \dot{I}_{3}=\dot{I}_{2_{-} S P}-\dot{I}_{3_{-} S P}=\frac{-\omega^{2} C_{2} R_{Z} M}{\left(Z_{1} Z_{2}+\omega^{2} M^{2}\right)\left(j \omega C_{2} R_{Z}+1\right)+j \frac{Z_{1}}{\omega C_{2}}} \dot{U}_{1_{-} S P} \\
& \dot{I}_{4}=\dot{I}_{3_{-} S P}=\frac{j \omega M}{\left(Z_{1} Z_{2}+\omega^{2} M^{2}\right)\left(j \omega C_{2} R_{Z}+1\right)+j \frac{Z_{1}}{\omega C_{2}}} \dot{U}_{1_{-} S P}
\end{aligned}
$$

Values of the currents flowing through the coil and capacitor on the transmitting and receiving side (Fig. 8) (Fig. 9). With the increase of mutual inductance, the peak points of current $\mathrm{I}_{1}$ slightly decrease and the peak points of current $I_{2}$ increase. These points are shifted to higher frequencies with increasing mutual inductance.

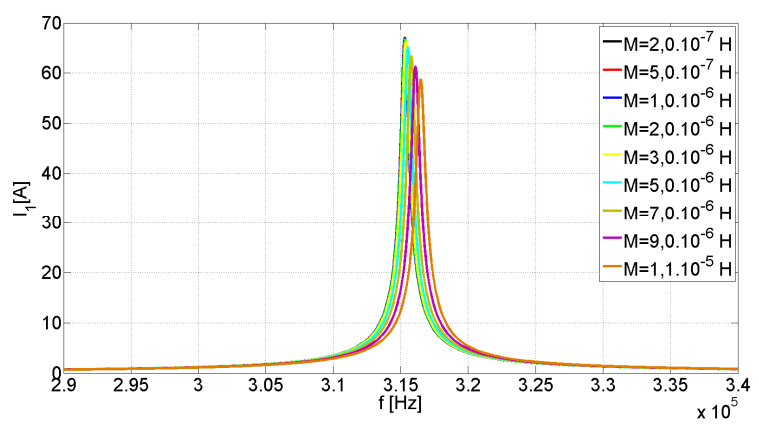

Figure 8. Frequency dependency of current $\mathrm{I}_{1}$ of WET system with series - parallel resonant compensation 


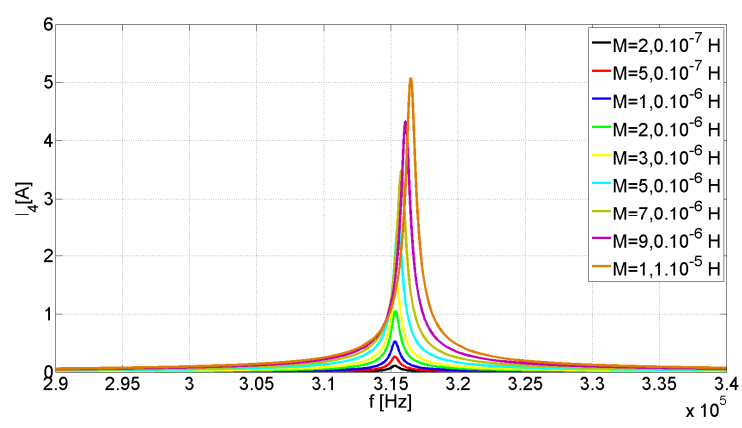

Figure 9. Frequency dependency of current $\mathrm{I}_{4}$ of WET system with series - parallel resonant compensation

Phase shift between power supply voltage $U_{1 \_s P}$ and current $I_{1}$ (Fig. 10) has only one zero value for each value of mutual inductance. These zero values are situated at frequency when transmitting power to the load is the maximum.

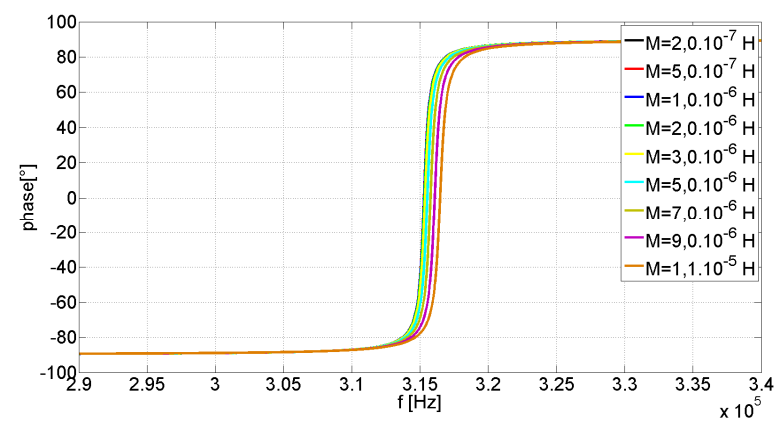

Figure 10. Phase shift between power supply voltage $\mathrm{U}_{1 \_} \mathrm{ss}$ and current flowing transmitting coil $\mathrm{I}_{1}$

On (Fig. 11) the dependency of transferred power for pure resistive load is shown. This power increases with the rise of $\mathrm{M}$, whereby maximum of power is shifted to the area of higher frequencies compared to the resonant frequency. Compared to S-S compensation, for the same values of mutual inductances, the transferred power for S-P compensation reaches much lower values.

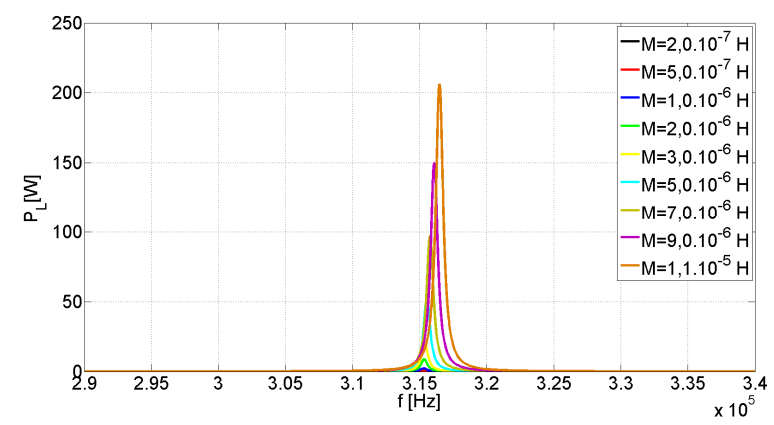

Figure 11. Frequency dependency of output power for WET system with series - parallel resonant compensation (variable parameter - mutual inductance $\mathrm{M}$ )

Frequency dependence of efficiency (Fig. 12) shows constant efficiency in wide range of frequencies. On the other side poor efficiency is the biggest disadvantage. The efficiency is significantly increased, if mutual inductance $M$ is reaching higher values (reduction of distance between coils). That means that the best efficiency can be reached for a short distances, while power transfer to the load is comparable with power transfer for series - series compensation.

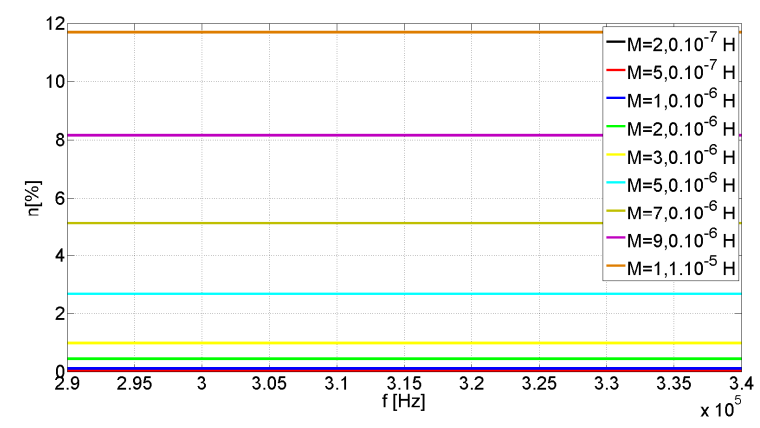

Figure 12. Frequency dependency of efficiency for WET system with series - parallel resonant compensation (variable parameter mutual inductance $\mathrm{M}$ )

\section{CONCLUSION}

This article shows differences between series series compensation and series - parallel compensation and important characteristics with respect to the target application which is charging accumulators in electric vehicles. Transferred power to the load for series - series compensation is comparable with series - parallel compensation, but efficiency for low values of mutual inductance is advantageous series - series compensation. Phase shift between voltage and current on the primary side shows good possibilities for control systems with maximum power point tracking. These results are used to optimize the design of the wireless energy transfer.

\section{REFERENCES}

[1] CHLEBIS P., HAVEL A., VACULIK P., PFOF Z.: Modern Instruments for increasing the Efficiency of the Energy Transfer in Electric Vehicles. In 14th International Power Electronics and Motion Control Conference (EPE-PEMC), Ohrid, Macedonia, 2010, pp. 89-93, ISBN 978-1-4244-7854-5

[2] VALCO, M., SINDLER, P., SEDO, J., KUCHTA, J.: Inverter Output Voltage Under Different Type of Loads, In: 10th International Conference ELEKTRO 2014, Rajecke Teplice, 2014, IEEE, pp. 383-388, ISBN: 978-1-4799-3720-2,

[3] LASKODY T., PRAZENICA M., KASCAK S.: Space Vector Pulse Width Modulation for Two-Phase Two-Stage Matrix Converter with Four Legs, In: Applied Electronics 2014, 19th international conference, IEEE, pp. 181-184, ISSN 18037232, ISBN 978-80-261-0276-2

[4] SPANIK, P., FRIVALDSKY, M., KANOVSKY, A.: Life Time of the Electrolytic Capacitors in Power Applications, In: 10th International Conference ELEKTRO 2014, Rajecke Teplice, 2014, IEEE, pp. 233-237, ISBN: 978-1-4799-3720-2,

[5] SPANIK, P., DRGONA, P., FRIVALDSKY, M., PRIKOPOVA, A.: Design and Aplication of Full Digital Control System for LLC Multiresonant Converter, In: Electronics and Electrical Engineering, Kaunas 2010,No. 10 (106), pp. 75-78, ISSN 1392-1215,

[6] HARGAS, L., KONIAR, D., HRIANKA, M: DICOM Standard and Virtual Instrumentation, International Conference Applied Electronics 2008, Pilsen, Czech Republic, 10-11th September, 2008, ISBN: 987-80-7043-6547, pp. 65-69.

[7] FRIVALDSKY, M., CUNTALA, J., SPANIK, P.: Simple and accurate thermal simulation model of supercapacitor suitable for development of module solutions, In: International Journal of Thermal Sciences, Elsevier, 2014, vol. 48, pp. 34-47, ISSN:1290-0729,

[8] KINDL, V.; KAVALIR, T.; PECHANEK, R.; SKALA, B.; SOBRA, J., "Key construction aspects of resonant wireless low power transfer system," ELEKTRO, 2014, vol., no., pp.303,306, 19-20 May 2014 